A PROCESS FOR PRESERVING THE PEARLOYSTER FISHERIES AND FOR INCREASING THE VALUE OF. THE YIELD OF PEARLS

From BULIETIN OF THE BUREAU OF FISHERIES, Volume XXVIII, rgo8 Proceedings of the Fourth International Fishery Congress : : Washington, I9o8
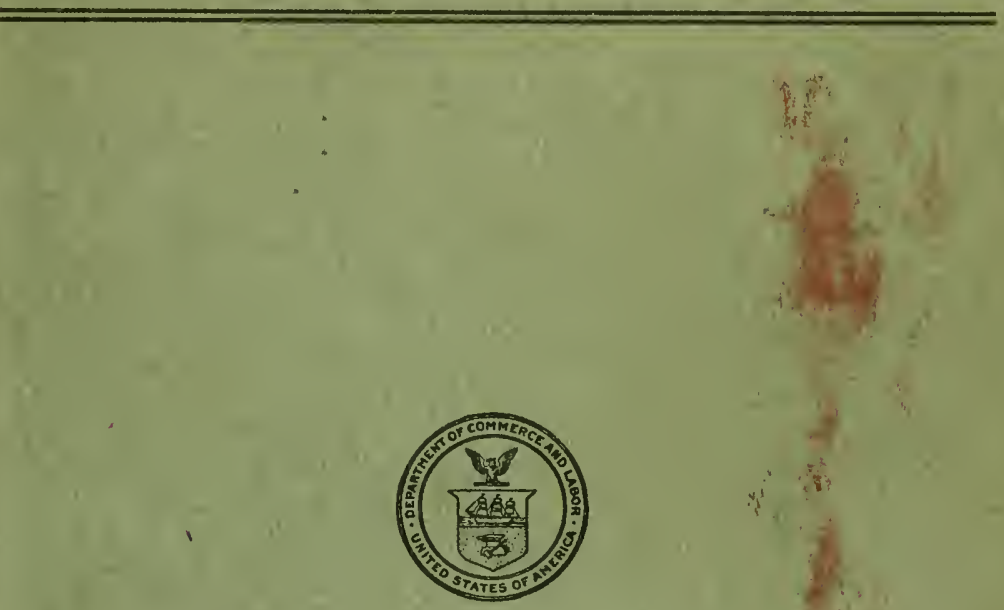

WASHINGTON : : : : : : GOVERNMENT PRINTING OFFICE $:::::: 1910$ 
कोल

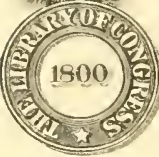

Class $S: 37^{6}$

Book $\quad 157$ 




\begin{tabular}{l} 
A PROCESS FOR PRESERVING THE PEARL- \\
OYSTER FISHERIES AND FOR INCREASING THE \\
VALUE OF THE YIELD OF PEARLS \\
\hline \hline
\end{tabular}

From BULLETIN OF THE BTREAT OF FISHERIES, Tolume XXYIII, IgOS

Procecdings of the Fourth International Fishery Congress : : IYashington, Igos

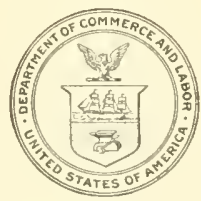

WASHINGTON $:: \quad: \quad: \quad:$ GOVERNMENT PRINTING OFFICE $: \quad: \quad: \quad: \quad: 1910$ 


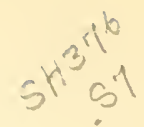

BUREAU OF FISHERIES DOCUMENT NO. 660

Issued February, 1910

$$
\text { MAR } 2 \text { lyIU }
$$


A PROCESS FOR PRESERVING THE PEARL-OYSTER FISHERIES AND FOR INCREASING THE VALUE OF THE YIELD OF PEARLS

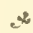

By John I. Solomon, B. Sc.

$+$

Presented before the Fourth International Fishery Congress, held at Washington, U. S. A., September 22 to 26, 1908, and awarded the prize of one hundred dollars in gold offered by the New York Academy of Sciences for the contribution, not entered in competition for any other award, which should be judged to have the greatest practical value to the fisheries or fish culture 



\title{
A PROCESS FOR PRESERVING THE PEARL-OYSTER FISHERIES AND FOR INCREASING THE VALUE OF THE YIELD OF PEARLS.
}

\author{
$*$ \\ By JOHN I. SOLOMON, B. Sc. \\ $*$
}

CONDITIONS IN THE PEARL-OYSTER FISHERIES.

The process of obtaining natural pearls is carried on throughout the world to-day in precisely the same manner that it has been done ever since mankind has prized this product of the sea as a gem. The only qualification that can be made to the above statement is that since the invention of modern diving apparatus there has been, in certain parts of the world, a modification in the method of securing the pearl oyster. This so-called improvement, however, has perhaps done more, within a very few years, to deplete former valuable natural beds than had centuries of previous fishings, when the ability of man to strip the beds of all the oysters they contained was prevented by the limitations of naked diving. The divers could then go to but comparatively shallow depths, and could gather the oysters only in a haphazard manner as they groped about for a minute or two at the bottom. Also, because of the inability of naked divers to carry on operations in any but calm and warm weather, the season for fishing was comparatively short. As a result of these conditions the beds in even comparatively shallow waters were never entirely stripped of all their oysters, while those lying at depths greater than the physical ability of the divers to reach were untouched. There were thus always sufficient oysters left for breeding purposes, and in spite of the wastes of the method for securing the pearls-the killing of all the oysters to get the contained pearls from about to per cent of then - the beds continued to give a comparatively uniform yield.

Since the adoption of diving apparatus the conditions have entirely changed. With the divers enabled to remain under water for a considerable period and in weather which would prohibit naked diving, and to go to greater depths and work in a thorough and systematic manner, the old natural beds have been completely stripped, and beds heretofore inaccessible liave been or are being depleted in the same way. This has already been accomplished in most parts of Australia, the waters off Thursday Island, Costa Rica, the Mergui Archipelago 
of Lower Burma, and in practically all the places heretofore fished by white men. The business in the East, excepting the fisheries of Ceylon and the Persian Gulf, where the local fisheries and conditions due to the nature of the oysters and other local influences are peculiar, is now practically in the hands of Japanese and Chinese, who alone are satisfied with the small returns from the now neager beds. The Europeans formerly engaged in the business are seeking other occupations. In Burma most of them have gone into tin mining, and at the present time just a single white man is there engaged in the pearl industry. In Australia and the islands of the East Indies there is a constant exploration now for virgin beds and a seeking for better divers and apparatus to go to greater and greater depths. There one hears a constant wail at the limitations of man and his apparatus to combat the great pressures of depths where the oysters are supposed still to be in abundance, and the more inaginative, speculative, or daring are now talking of submarines to go after the oysters. In this connection I would state that a submarine of special construction has recently been built in France for sponge fishing in the Mediterranean oft the coast of Algiers.

As a result of the wastes of past and present methods and the general conditions of the industry as now carried on, both in the pearl fisheries of the seas as outlined above, and in connection with the fresh-water pearl fisheries of the United States and other countries, the statement has been freely made in the past few years by prominent pearl dealers of Europe and America that no large pearls will ever again come to market, except those in the possession of eastern magnates and potentates who may be induced by the extravagant prices offered to part with heirlooms held in their families for generations. In other words, the pearl of size and value is tending to cxtinction. Although the scientific propagation of oysters and other sliellish lias been made a great commercial industry in Europe and America, the idea of conserving the pearloyster beds and attacking the problem of securing pearls and shells other than by the ruthless destruction of the natural beds secms never to have entered the minds of those engaged in the industry. I have never received any encouragement from a single one of them with whom I have corresponded or whom I have met; and although the installation whiclı I liave 11 ryself started has proved the undoubted soundness and utility of the process, and the fact of its establishment has now becone more or less known throughout the East, I have yet to learn of the interest of any individual or corporation engaged in the pearling industry. In view of the recent agitation in the United States because of the destruction of the fresh-water mussel pearl fislieries, I hope that in my own country n110re interest will be disclosed.

PRINCIPLE OF THE PROCESS.

An electrical engineer by profession, ny first knowledge of the pearling industry was gained through an acquaintance with a family having social and 
business relations with Colombia, Panama, and Costa Rica, who thereby had a knowledge of and who dealt in pearls fished in the waters of those countries. It was because of this acquaintance and the knowledge thus gained of the conditions that I conceived the idea of utilizing the $\mathrm{X}$ ray for preventing the losses and wastes of present pearling metlods and for increasing the yield of fine pearls. In this connection, I would state that I an not the first to liave thought of utilizing the I ray for tliese purposes. Although I did not know it until later, Prof. Raphael Dubois, of the University of Lyons, had a few years before suggested sucli a use of the I ray. I liad the pleasure, in the month of December, 1907, of paying a visit to Professor Dubois. But from a particular question asked by hin I found tlat his investigations liad been slight and not very extensive on living oysters.

The question asked by Professor Dubois was one which I had great difficulty in explaining away to the laymen whow I induced to become financially interested in my enterprise, "Will the $\mathrm{X}$ rays kill the oysters?" I had made this test at the very commencement of my experiments, once I had become enabled by skillful exposure to disclose pearls which I had placed inside of large Rockaway oysters in New York. Having previously made arrangements at the New York Aquarium, I placed in tanks there live oysters which I had subjected to continuous exposure of powerful $\mathrm{X}$ rays for as long as a period of ten miuutes. These oysters lived for months without showing any ill effects whatever. In my process the time of exposure is not one-tenth of this. I made this experiment ouly in order to satisfy the minds of my subscribers, for, after consultation with specialists having a fill knowledge of the plyysiological and pathological effects of $\mathrm{X}$ rays on animal tissues and organisus, I was myself convinced that the slight exposure necessary for the process could have no effect.

My first intention and experiments were with the idea of using the fluoroscope for the detection of the pearls within the living oysters, but llaving learned that in Ceylon they had taken as many as $41,000,000$ oysters at a single fishery (one season) I saw that the conditions were not as in Costa Rica and some other places. I accordingly adopted a radiographic method. A comparatively few oysters may be examined individually and carefully by means of the fluoroscope, bit by the other method great numbers may be automatically handled and many inspectors may leisurely examine radiograplis made practically automatically; and the radiographic method in practice has done all I expected it to do. In the same time that would be required to examine a single oyster by the fluoroscopic method a single tube and operator can make radiograplic images of hundreds of oysters, and, as has been found in surgical work, a radiograpl will show up more minute particles and detail than can ever be disclosed by a fluoroscopic examination.

In order to accomplish the object sought, I had to devise a process and apparatus, and I subjoin hereto a description and the claims of the first of several 
patents which have been granted to ine by the governinents of Australia, Ceylon, India, Japan, and other pearl-producing countries, or countries which have pearl-producing colonies and dependencies.

\section{DESCRIPTION OF INVENTION AND CLAIMS AS PATENTED.}

The object of this invention is (1) to provide means for taking radiographs or of making fluoroscopic examinations of separate pieces of matter or objects in considerable quantities, so that they may be taken simultaneously for the purpose of making radiographic examination of these objects and pieces of matter, and then (2) readily to identify each radiograpls as being that of the particular object or piece of which it is the representation.

The manner of taking radiographs at present is to make exposures of individual objects placed upon photographic plates, or other sensitive radiographic media, either in direct contact or with the plate properly inclosed in paper to keep out light. The exposures having been made, by means of the $\mathrm{X}$ rays, Röntgen rays, or any other rays penetrating matter opaque to light, the object is removed from the plate or other sensitive nedium and set aside, the sensitive medium being then developed through ordinary photographic process and examined.

This method is cumbersome and expensive, and precludes the radiographic examination of many different materials. Also it can not be utilized in connection with large bodies or numbers of objects for commercial purposes. My particular aim in connection with the present invention is the ascertaining of the presence of pearls of any size or form in pearl oysters (Margaritifera vulgaris) without injury to the oysters; but the invention is not limited with respect to the character of the objects under examination, as it may be used for any objects whatever. Ordinary processes and apparatus could not be used for this purpose, for the reason that they would be too cumbersome, slow and expensive, and entirely unsuited.

For the purpose of examining the material quickly and cheaply, I utilize a tray or conveyer of considerable surface, over which the material may be spread or carried, and this tray or conveyer is then laid upon the sensitized radiographic medium. The latter is of a size larger in area than the tray or carrier itself, the excess being sufficient to allow for the distortion due to the rays falling upon the outer area at a considerable angle.

The exposure having been made, the tray is lifted from the sensitized medium, or in the event of the conveyer it is so adjusted as to be earried beyond the sensitized inedium. The latter is then developed, and the resultant radiograph, which is the full size of the tray, except for the increase in size due to the distortion, can be compared to the objects or material on the tray itself, these objects or material not having been disturbed, and oceupving at this time the same relative position as in the particular radiograph on the sensitized medium. 
When pearl oysters are the objects examined, the pearls will clearly appear in the radiograph, as they obstruct the passage of the rays to a greater extent than other portions of the oysters. I also use in connection with the tray or conveyer a means for identifying the particular group of objects which have been radiographed so that the radiograph may be afterwards compared with the objects on the tray and their identity established. With pearl oysters, those that have pearls may thus be identified, and the position and size of the pearls be ascertained, without destroying the oysters.

The essentials of the tray bottom or conveyer are two: (1) That the material be composed of a substance which renders litthe or no resistance to the passage of the $\mathrm{X}$ rays, Röntgen rays, or any other rays penetrating matter opaque to light, and allows

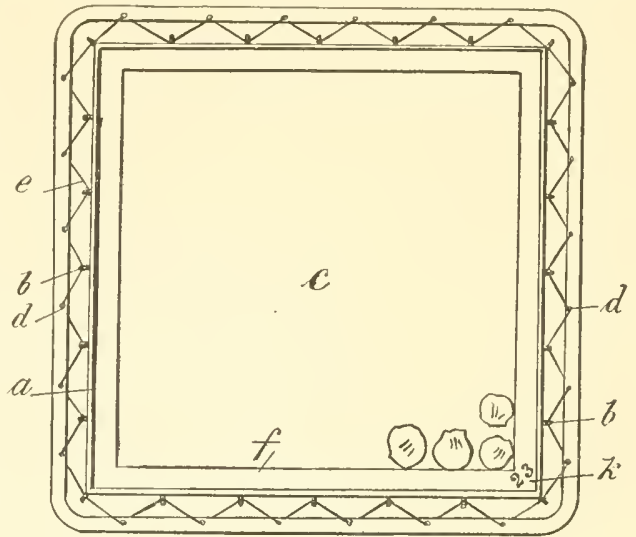

FIG. 1.-Plan of tray to contain pearl oysters for radiographing. them to affect the sensitized medium practically as though it had not been interposed; and (2) that the tray bottom be as thin as possible, in order that the matter when held on it be but little further away from the sensitized medium when on the tray than when placed directly on the sensitized medium, so that as good definition as possible may be obtained.

The tray may be of any shape or size desired, and may be constructed of

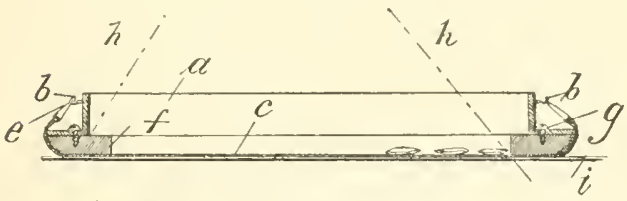

Fig. 2.- Longitudinal section of tray shown in figure I cork, fiber, wood, fabric, aluminum, celluloid, vulcanized rubber, or any other material the qualities of which, as outlined above, are such as to afford the least amount of resistance to the rays. That wet objects may be examined without warping or distortion of the tray, I propose that a tray be made with the bottom of canvas, duck, or other such fabric. Such a receptacle is shown in the attached drawings, of which figure $I$ is a plan and figure 2 a longitudinal section. It consists of a rigid frane $(a)$ made of strips of metal, wood, or other suitable material, and having hooks or pins $(b)$ 
on the outside. The canvas $(c)$ can then be placed under this frame, and having suitable eyelets $(d)$ in its edge, can be stretched tightly upon the frame by a lacing $(e)$ which is passed through the eyelets $(d)$ in the canvas $(c)$ and the looks or pins $(b)$ on the frame. In order that the radiographs of objects along the sides may be complete and properly made, and be not intercepted by this frame $(a)$, another frame $(f)$, of wood or other material wlich will allow the rays to pass through, is placed between the canvas and the first frame $(a)$ and secured to the latter by means of serews $(g)$. The frame $f$ projects sufficiently inside of the frame $a$ to hold the materials that are being examined at such a distance that the rays $(h)$ pass through the very outside of the material, clear of the frame $a$, and will produce the desired effect upon the sensitized medium (i) underneatli the tray.

Upon the tray and preferably upon the second frame $(f)$, or upon the canvas, is placed a number, letter, or some other device by whieh to distinguish the trays from each other. This $\operatorname{sign}(k)$ is here shown as a number (23), cut out of metal,

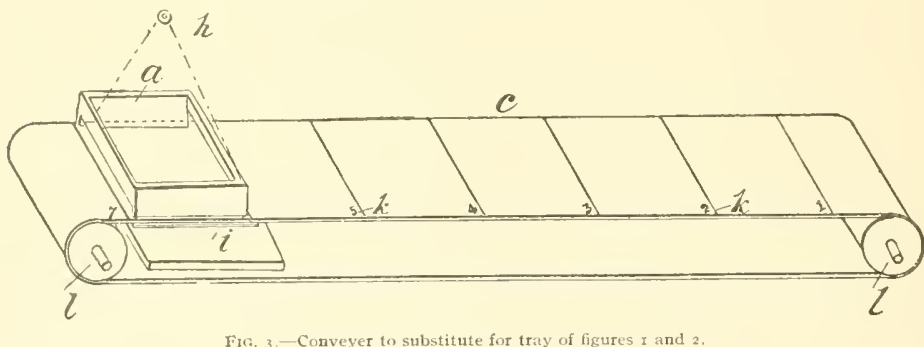

which is impervious to the ray, and properly secured to the frame $f$ or the canvas.

The invention may be modified, as, for instance, by substitution of a conveyer in place of the tray. One form of conveyer is shown in figure 3 . Here the canvas $(c)$ is an endless strip passing over rollers $(l l)$. The frane $(a)$ is shown as raised above the canvas a sufficient height to allow the objects placed upon the canvas to be moved under it. The eanvas is in divisions equal in size to the frame, and each division is provided with a distinguishing mark $(k)$, as already described. In operation of this modification, the objects are placed within the frane and upon one division of the conveyer. The sensitized medium (i) is placed under it as shown, and the radiograph is then taken. The conveyer is then moved by turning one or both of the rollers, so that the objects will have passed to one side and an uncovered portion of the conveyer is exposed. More objects are placed upon this within the frame, and a seeond radiograph is taken. This will be repeated, the first radiographs being developed while others 
are being taken. The conveyer belt should be sufficiently long to allow the developed radiograph to be secured and examined with the corresponding original objects without disturbing the continuity of action of the machine. Each radiograph will have printed upon it the distinguishing character of that portion of the conveyer, and the different objects may be identified before they are disturbed.

A further modification of the invention may be made by utilizing the principles of the fluoroscope. In this form, in place of the sensitized medium would be used the ordinary fluoroscope screen, formed of any suitable material, as, for instance, the tungstate of barium or of strenium, in crystallized form, or barium platinum cyanide. The conveyer carrying the objects should in this case be placed between the $\mathrm{X}$-ray tube and the fluorescent screen.

Having now particularly described and explained the nature of my invention, and in what manner the same is to be operated, I make the following claims therefor:

(1) The herein described process of examining separated matter or different objects, such as pearl oysters, in quantities, which consists in placing them upon a suitable support of a claracter that will not obstruct or only slightly obstruct the passage of I rays, Röntgen rays, or any other rays penetrating matter opaque to light; placing the sensitized medium below the support and exposing the objects and medium to the action of the rays; removing the support without disturbing the positions of the objects and then developing the sensitized medium, whereby a radiograph of the objects will be obtained, which can be compared with the objects without disturbing them.

(2) In an apparatus for examining matters or objects in bulk, the combination with a support for the objects, the said support being formed of material readily penetrable by the rays, and having upon it a distinguishing mark, made of material not penetrable, in combination with a means for producing rays.

(3) An improved tray, made of material which is of such quality and dimensions as will permit objects to be placed thereon and readily radiographed as though such tray had not been interposed between such objects and the sensitized medium.

(4) The combination with a tray of canvas $(c)$ and a rigid frame $(a)$ to which the canvas is stretched.

(5) The combination with the bottom and frame of a tray and a second frame above the bottom, the said second frame being for the purpose of keeping the matter which is examined a sufficient distance away from the first frame, in order that the rays passing through such matter will fall clear of the first frame and upon the sensitized medium.

(6) The combination with a conveyer and a frame of means for supporting the sensitized medium below the conveyer, and means for producing rays and securing a radiograph upon the sensitized medium. 
(7) The use of a fluoroscope in connection with any form of deviee shown in the drawings or covered by the preceding elaims.

In addition to having to devise a special method, of which the above is a description, it was necessary to adopt radiographic apparatus and materials of such a nature as to make the methods and costs of the process commercial. For instance, it was necessary to be able to make $X$ ray exposures over a large area in order to include suffieient oysters at an exposure, an area larger than had been before attempted or rather required in the field of surgery, in which I found the use of the $\mathrm{I}$ ray exclusive when I commenced my investigations; also photographic material of a nature and cost suitable for the work had to be sought. Without going into details, I may say that I overcame the various difficulties, as I believe the accompanying exhibits prove. ${ }^{a}$

\section{PRACTICAL DEMONSTRATION OF THE PROCESS.}

After considerable correspondence, I went to Ceylon to start my enterprise, and established my equipment on the island of Ipantivu, in the northwestern Province of Ceylon, and near to the famous pearl fishery of the Gulf of Manaar. I lave there invested in buildings, maehinery, boats, equipment, and photographic supplies the sum of nearly $\$ 50,000$, some of it my own money, but most of it subseribed by different people in smaller or larger amounts, to whom I or my friends had explained my ideas and the possibilities therefrom. I proposed to get oysters when they were freshly fislied, and instead of indiscriminately killing all in order to get the pearls of value contained in the few, to subject the oysters to the process. Those found to contain pearls of value could be immediately opened; those containing small pearls of but little or no value, could be planted under suitable conditions to remain until they had become older and larger, and the contained seed pearls also larger and of value; while those found to contain no pearls could be returned to the sea either in

$a$ The following exhibits were appended to the manuscript submitted by the author:

Exhibit A, showing a part of the installation on Ipantivu Island-the water distilling building and chimney, the process building, and bungalow.

Exxhibit B, showing a panoramic view of the installation.

Exhibit C, showing coolies arranging oysters in trays.

Exhibit D, showing coolies carrying trays of oysters up to the process building to be subjected to the X ray.

Exhibit E, a small radiograph of some growing oysters containing pearls.

Exhibit F, a small string of seed pearls

Exhibit G, a radiograph of an oyster containing a seed pearl of a larger size and a string of pearls of which Exhibit $F$ was a part. Note the line down the center of the pearls showing the drilling. Undrilled, in their ratural state, these pearls would show up even more clearly.

Exhibit $\mathbf{H}$, a part of a full-size radiograph showing some oysters containing small seed pearls.

Exhibit I, a full-size but only partly "fixed" radiograph of 120 oysters, showing number of tray made by lead number thereon, and arrangenent of oysters in regular rows by means of which the oysters held on the trays are identified. The marks made by the inspector for seed pearls, large pearls, or obscurity, or for other things are also shown. 
the hope that they would become inoculated with the pearl-inducing cestode or at least to propagate and maintain the growth of oysters on the banks.

The inmediate objects in view were therefore-

(I) The prevention of the theft of pearls from the rightful owners of the oysters.

(2) A great increase in the yield of valuable pearls from a given number of oysters.

(3) The maintenance of the yield of oysters from the natural beds, if not a positive increase therefrom, as against the destruction of the fisheries under present methods.

In actual working the radiographs are brought wet out of the process building, wherein all exposure and developments are made in "clark-room" light, and with good light and the wet radiograph practically nothing can escape. It is easier to disclose that an oyster contains a pearl than actually to extract the pearl. If the process errs, it errs on the side of safety. We find that we set apart many oysters as containing seed pearls, which further examination slows contain none, but that what was shown in the radiograpl was an imperfection in the film, an air bubble, a piece of coral outside the slell, etc. With practice, eren these mistakes can be eliminated, but they are not of such a nature as to make us lose or eliminate an oyster which has the possibility of developing a valuable pearl. With sufficient and proper help and auxiliary appliances, the plant on Ipantivu Island, with its single tube equipment, can radiograph up to too oysters per minute. These thin-shelled, small Ceylon oysters (Margaritifera vulgaris) are easy to handle. But we can attain just as nuch success with the fresh-water mussels of the United States and other countries, and with the larger Margaritifera maxima peculiar to Australia, Burma, etc. In fact my first experiments were made on these. IVe can not, of course, do so many at a time or so quicliy, as they require a longer time of exposure, but on the other land, the product is of much greater value. My plant on Ipantivu Island has completely fulfilled all expectations, and, so far as concens the possibility of radiographing pearl-bearing oysters on a commercial scale in order to disclose the contained pearls and without injury in any way to the oysters, has proved ny process to be a complete success.

Unfortunately, owing to certain conditions which arose after I came to Ceylon and invested iny capital, and which have prevented my getting live oysters, I have up to now been unable to prove the next and equally important stage of my process. However, as to whether pearl oysters known to contain seed pearls can be kept uncler such conditions as will make them continue to live and grow and thrive, and the majority of the contained seed pearls likewise to increase in size and consequent value, I leave it to the nembers of the International Fishery Congress to decide. 


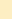






